\title{
Advances in the Management of Acute Cardiorenal Syndrome in China: Biomarkers for Predicting Development and Outcomes
}

\author{
Fan Fan Hou Xiaobing Yang \\ Division of Nephrology, Nanfang Hospital, Southern Medical University, National Clinical Research Center for \\ Kidney Disease, State Key Laboratory of Organ Failure Research, Guangzhou, China
}

\section{Key Words}

Acute cardiorenal syndrome - Acute kidney injury ·

Angiotensinogen · Biomarker · Prediction

\begin{abstract}
Background: Acute cardiorenal syndrome (CRS) is a common clinical condition associated with adverse outcomes. Early identification of acute kidney injury in this setting remains challenging given that serum creatinine level is a marker of renal function and not kidney injury. Summary: Several renal injury-related molecules are now available, which may help elucidate the complexities of the organ crosstalk, enabling more accurate risk stratification and effective interventions. Key Messages: This review highlights the major studies that have characterized the diagnostic and prognostic predictive power of these biomarkers with reference to acute CRS. Although more research is needed, the current results are very promising.
\end{abstract}

(c) 2016 S. Karger AG, Basel

For Cardiorenal Syndrome in Western Countries, see Ronco and Di Lullo, Kidney Dis 2016;2:151-163.

\section{KARGER}

E-Mail karger@karger.com

www.karger.com/kdd

\section{Introduction}

Renal and cardiac diseases frequently coexist. The clinical entity of the cardiorenal syndrome (CRS), which encompasses patients with heart failure, is the most commonly encountered clinical scenario that exemplifies the interaction between the heart and the kidney. A five-subtype classification of CRS has been proposed: type $1=$ acute heart failure resulting in acute kidney injury (AKI); type 2 = chronic cardiac dysfunction causing progressive chronic kidney disease (CKD); type 3 = an abrupt and primary worsening of kidney function causing acute cardiac dysfunction; type 4 = primary CKD contributing to cardiac dysfunction, and type $5=$ acute or chronic systemic disorders that cause both cardiac and renal dysfunction [1].

Patients with acute decompensated heart failure (ADHF) often develop worsening renal function (WRF) in the course of the disease, which is termed 'acute or type 1 CRS' [2]. Acute CRS occurs in $25-40 \%$ of patients admitted with ADHF in Europe and the United States and in $32-44 \%$ of patients in China, depending on the criteria used [3-5].

The relevance of the kidney in heart failure is obvious, as it serves as the regulator of fluid and sodium balance. 
Renal dysfunction is central to the development of volume retention, which is a hallmark of the heart failure syndrome [6]. Thus, it is not surprising that AKI or WRF has repeatedly been demonstrated to be one of the strongest predictors of adverse outcomes in ADHF patients [7, $8]$. The annual mortality rates for $\mathrm{ADHF}$ are $26 \%$ in patients without renal injury, $41 \%$ in patients with any impairment of renal function, and $51 \%$ in those with moderate-to-severe renal dysfunction [9].

Despite widespread recognition of the importance of acute CRS, progress toward an understanding of this syndrome has remained a challenge [3]. The bidirectional interaction between the heart and the kidney is complex with proposed mechanisms ranging from hemodynamic change, endothelial dysfunction, and neurohormonal activation to dysregulation of salt and water balance $[1,10]$. Renal dysfunction can result from irreversible nephron loss secondary to preexisting CKD, or it can be induced by heart failure itself. Furthermore, there is evidence that heart failure is associated with structural damage in both organs leading to a worse prognosis [11]. It is, therefore, not surprising in the face of these challenges that the majority of cardiorenal trials have been disappointingly negative [12-15].

However, renal injury biomarkers have the potential to inform some of the intricacies involved in assessing cardiorenal interactions and provide opportunities to overcome these challenges. The novel biomarkers for CRS can help to early detect AKI and predict the prognosis in the setting of ADHF.

\section{Biomarkers for Predicting Development of AKI in Acute CRS}

ADHF is one of the major causes of acute CRS. A major barrier to improving the clinical outcomes in such patients is the difficulty in identifying those at high risk of AKI early enough to initiate beneficial interventions. It is well recognized that serum creatinine is not an early marker of renal injury, as AKI heralded by a rise in serum creatinine cannot be diagnosed until $24-48 \mathrm{~h}$ after the initial insult. The use of biomarkers to aid in the early detection of AKI or WRF has emerged as an area of increasing scientific interest.

Neutrophil gelatinase-associated lipocalin (NGAL) is a $25-\mathrm{kDa}$ transport protein expressed by neutrophils and epithelial cells, including those in the proximal convoluted tubule [16]. NGAL is detected in human blood and urine at the earliest stage of AKI, 48-72 $\mathrm{h}$ before the rise in creatinine. Although the role of NGAL in detecting AKI early has been shown in adults across all settings [17], only small-scale clinical studies have tested the utility of this biomarker in predicting acute CRS and have gained inconsistent results. In one study, 91 patients with $\mathrm{ADHF}$ and serum NGAL $>140 \mathrm{ng} / \mathrm{ml}$ at hospital admission had a 7.4-times higher likelihood of developing WRF [17]. Another study reported a similar relationship using a cutoff for serum NGAL $>170 \mathrm{ng} / \mathrm{ml}$, resulting in an area under the receiver operating characteristic curve (AUC) for WRF of 0.93 [18]. A prospective observational study of ADHF also demonstrated that admission NGAL $>89 \mathrm{ng} / \mathrm{ml}$ predicted AKI with an AUC of 0.71 [19]. Urinary NGAL was associated with AKI, albeit less powerfully (AUC $=0.78)$, in our prospective cohort of 317 patients admitted with ADHF [20]. A recent study reported that serial measurements of serum NGAL in ADHF seem to improve its performance for predicting WRF, where the degree of change in NGAL from baseline to peak yields an AUC for WRF of 0.91 as compared to admission NGAL alone (AUC $=0.69$ ) [21]. Results reported to date, however, are by no means conclusive. In a cohort of 207 patients with acute heart failure, although an elevated plasma NGAL level predicted the occurrence of AKI in a univariate analysis, it was not an independent predictor of AKI after controlling for preexisting chronic cardiac or kidney disease in a multivariate analysis [22]. Similar results have been observed in other studies, where NGAL levels were not associated with changes in renal function in the setting of heart failure $[23,24]$. Interestingly, a recent study found that the performance of urinary NGAL for predicting AKI was modified by the baseline renal function [25]. The circulating NGAL levels may also be influenced by various extrarenal factors such as infectious disease and anemia $[26,27]$. Further research is necessary to understand these findings and to determine whether appropriate stratification based on characteristics of patients would improve the predictive performance of NGAL for acute CRS.

Increasing evidence has revealed that the intrarenal renin-angiotensin system (RAS) plays a vital role in maintaining hemodynamic balance and cardiorenal interaction, which are often disrupted in patients with ADHF [28]. Intrarenal angiotensinogen (AGT), a principal substrate of the local RAS, is mainly formed in proximal tubule cells. The urinary AGT level has been shown to be an indicator of intrarenal RAS activity in both animal and clinical studies [29]. We have recently reported an excellent performance of urinary AGT for the early prediction 
of AKI in a prospective, two-stage, multicenter cohort study in 436 patients with ADHF [20]. In patients with the highest quartile of urinary AGT $(>148 \mu \mathrm{g} / \mathrm{gCr})$ on admission, the risk for development of AKI increased 50fold compared to those with the lowest quartile of urinary AGT $(<10 \mu \mathrm{g} / \mathrm{gCr})$. For the prediction of AKI, urinary AGT (AUC $=0.84$ ) outperformed urinary NGAL $(\mathrm{AUC}=0.78)$, urinary albumin/creatinine ratio (AUC $=$ $0.71)$, and the clinical risk model $(\mathrm{AUC}=0.77)$ in this study. Interestingly, urinary AGT levels are associated with incident AKI in patients both with and without preexisting CKD. In contrast with urinary NGAL, which best identifies AKI in patients with an estimated glomerular filtration rate (eGFR) in the range of 90 to $120 \mathrm{ml} / \mathrm{min}$ [25], the predictive performance of urinary AGT is better in individuals with an eGFR $<60 \mathrm{ml} / \mathrm{min}$. This unique characteristic of urinary AGT makes it a useful predictor of AKI, in particular among those with acute-on-chronic renal injury, which accounts for $30-45 \%$ of WRF in $\operatorname{ADHF}[4,30]$.

Other renal injury biomarkers have been tested in CRS. N-acetyl- $\beta$-D-glucosaminidase (NAG), a large lysosomal enzyme originating in proximal tubular cells, is indicative of tubular injury when detected in the urine [31]. Elevated NAG is associated with congestion as tested by brain natriuretic peptide (BNP) and atrial natriuretic peptide and decreases in response to diuretic-induced decongestion [32]. Although baseline NAG was predictive of WRF in the GISSI-HF trial in a univariate analysis, it lost statistical significance after covariates adjustment [33]. Furthermore, although elevated urinary NAG was correlated with tubular injury, it was not specific for CRS, as it also increased in patients with diabetes and hypertension [33].

Interleukin-18 (IL-18) is a cytokine that is produced in mononuclear cells, macrophages, and nonimmune cells. In the kidney, IL-18 is produced and released from the proximal tubule epithelial cells within hours of kidney injury [34]. In heart failure, there have been few studies examining IL-18. In a cohort of 83 patients admitted for ADHF, IL-18 was only modestly correlated with other kidney injury biomarkers and, when adjusted for urine creatinine, showed no correlation with eGFR [35].

Kidney injury molecule-1 (KIM-1) is a type I cell membrane glycoprotein expressed in regenerating proximal tubular cells. Urinary KIM-1 levels are elevated depending on the severity of heart failure [36]. However, KIM-1 levels are only slightly elevated on hospital admission in ADHF and do not predict subsequent AKI [35].

\section{Biomarkers for Predicting Progression of AKI in Acute CRS}

Although most patients who develop acute CRS experience a mild form of AKI (e.g. KDIGO/AKIN stage 1 or RIFLE R) and do not progress to more severe AKI (KDIGO/AKIN stage $2 / 3$ or RIFLE F) or do not require dialysis, approximately $29-48 \%$ of these patients progress to a higher stage of AKI $[37,38]$. Recent studies have demonstrated that the risk of mortality exponentially increases with increasing stages of AKI in ADHF [39]. Early detection of patients at a higher risk for AKI progression would help physicians to plan and initiate the appropriate managements to improve the renal safety of therapies, augment surveillance of cardiac and renal dysfunction, and develop renal-preserving treatments $[40,41]$.

Unfortunately, predicting which CRS patient will suffer progressive AKI is clinically challenging. In patients with ADHF, fluid retention, low protein intake, and decreased creatinine production secondary to muscle atrophy may dissociate creatinine levels from reflecting the true severity of renal dysfunction. Diagnostic mainstays such as the fractional excretion of sodium and urea have been shown to be suboptimal [42-46]. Assessment of biomarkers for renal tubular injury at the time of creatininebased diagnosis of AKI offers information on the progression of AKI in multiple settings such as cardiac surgery, intensive care unit, transplantation, and cirrhosis [47-52].

In patients with AKI after cardiac surgery and in the intensive care unit, elevated urinary AGT is associated with progression to higher stages of AKI $[49,53]$. In a recent prospective multicenter study of acute CRS, we evaluated the performance of 6 renal injury biomarkers measured at the time of AKI diagnosis for predicting progression of AKI in 213 patients who developed KDIGO stage 1 or 2 AKI [54]. The progression of AKI was defined as worsening of AKI stage. In this study, increase in serum creatinine, the current hallmark for recognizing AKI, was not associated with the risk of AKI progression. However, there was a clear correlation between levels of urinary AGT, NGAL, and IL-18 and the risk of AKI progression after multivariable adjustment. Critically, these renal injury biomarkers, especially urinary AGT, showed a large effect size (category-free net reclassification improvement $>0.6$ ) to improve the risk classification for AKI progression and AKI progression with subsequent death beyond the clinical model alone, suggesting that urinary AGT, NGAL, and IL-18 measurement at the time of AKI diagnosis forecasted the progression of AKI in ADHF. This study did not find any benefit of plasma NGAL, uri- 
nary KIM-1, and urinary albumin/creatinine ratio measurements for predicting AKI progression in multivariable analysis, although prior reports have shown that these biomarkers may predict worsening of AKI in other clinical settings $[47,48]$.

\section{Biomarkers for Predicting Outcomes in Acute CRS}

In patients with $\mathrm{ADHF}$, the presence of coexistent renal insufficiency portends a grave prognosis. In addition to an increase in the risk of mortality, AKI superimposed on CKD accelerates CKD progression. AKI is associated with an increased risk of end-stage renal disease $[55,56]$.

The ability of NGAL to predict outcomes has been examined in acute CRS. In a multicenter prospective study of ADHF, elevated plasma NGAL at the time of discharge was a strong prognostic indicator of 30-day outcomes (all-cause mortality and readmissions for acute heart failure) [57]. In a cohort of 231 patients with acute heart failure, admission NGAL $>170 \mathrm{ng} / \mathrm{ml}$ was associated with increased mortality during a 6-month follow-up period with an AUC of 0.77 [58].

NGAL also may have a role in the chronic aspects of the CRS. A study reported that both serum and urinary NGAL independently predicted CKD progression which was defined by a doubling of serum creatinine or occurrence of end-stage renal disease $[55,56]$. These findings suggest that NGAL could be used to identify patients who are at high risk for adverse outcomes and could help in the risk stratification for acute CRS.

Urinary AGT has been recently described as a novel prognostic biomarker of AKI. Increase in urinary AGT is associated with adverse outcomes, such as increased length of hospital stay, requirement for renal replacement therapy, and death $[49,53]$. In our recent study of 317 patients with ADHF, a level of urinary AGT $\geq 55 \mu \mathrm{g} / \mathrm{gCr}$ on admission was associated with a significantly increased probability of all-cause mortality (HR 4.7; 95\% CI 2.78.2) and rehospitalization (HR 3.7; 95\% CI 2.2-6.6) over the 1-year follow-up period. Interestingly, we recently found that elevated urinary AGT during acute CRS predicts the transition from acute to chronic renal injury, suggesting that increased intrarenal AGT during AKI may promote the progression of AKI to CKD.

Further studies have examined the role of other biomarkers in predicting outcomes of acute CRS. Although IL-18 does not predict WRF during hospitalization, it is the biomarker significantly associated with persistent renal impairment following discharge; baseline levels $>7$ $\mathrm{pg} / \mathrm{gCr}$ were $68 \%$ sensitive and $60 \%$ specific [35]. KIM-1 is associated with an increased risk of heart failure hospitalization and all-cause mortality in chronic heart failure $[11,36]$. In ADHF, however, there is no relationship between the levels of KIM-1 on admission or during hospitalization and 180-day all-cause mortality $[35,59]$.

\section{Application of Biomarkers to Acute CRS}

The natriuretic peptides have aided with the diagnosis and management of ADHF. These classic cardiac markers, as well as the prognostic markers such as mid-regional proadrenomedullin, have demonstrated the potential of a multiple-biomarker approach to ADHF [60]. However, much of the morbidity associated with ADHF comes from the coexistence of AKI not just with the pathophysiological mechanisms but also with the pharmacological treatments. With the combination of renal injury biomarkers and cardiac markers, a multimarker approach to acute CRS that provides insights into both cardiac and renal dysfunction would lead to a more precise risk stratification and more appropriate management. In our cohort of ADHF patients, those with admission levels of urinary AGT $\geq 55 \mu \mathrm{g} / \mathrm{gCr}$ and an NT-proBNP level $>5.5 \mathrm{ng} /$ $\mathrm{ml}$ had the highest overall mortality and the highest rate of failure of renal recovery at discharge [20].

The application of renal biomarkers to the management of ADHF may provide additional information guiding treatment. For example, diuresis is commonly used for decongestion. Vigorous diuresis may lead to a decline in renal perfusion and even a rise in serum creatinine. The application of renal injury biomarkers may enable precise treatment of this patient group, as it can differentiate between the hemoconcentration-induced reduction in GFR and renal tissue injury (i.e. AKI); in the latter condition, diuretic therapy could be reduced or withheld. Similarly, a role of renal injury biomarkers could be considered when other therapies are used to treat acute CRS. For example, measurement of urinary AGT could play a role in identifying patients with AKI who are likely to progress to CKD and could potentially benefit from RAS blockade.

\section{Conclusion}

There is a growing literature of promising and novel renal injury biomarkers for acute CRS. Although research has so far focused on their utility in diagnosis and prognosis, it is likely that through continued study in this area 
an understanding of the specific mechanisms involved in cardiorenal dysfunction will allow patient-specific therapeutic approaches in the future.

\section{Acknowledgements}

This work was supported by the Major State Basic Research Development Program of China (2012CB517703 to F.F.H.), the National Natural Science Foundation of China (Key Program;
81430016 to F.F.H.), the National Key Technology Support Program of China (2013BAI09B06 and 2015BAI12B07 to F.F.H.), the National Nature Science Foundation (81670636 to X.Y.), and the Major Scientific and Technological Planning Project of Guangzhou (15020010 to F.F.H.).

\section{Conflict of Interest Statement}

All the authors declare no competing interests.

\section{References}

1 Ronco C, Haapio M, House AA, Anavekar N, Bellomo R: Cardiorenal syndrome. J Am Coll Cardiol 2008;52:1527-1539.

2 Ronco C, Cruz DN, Ronco F: Cardiorenal syndromes. Curr Opin Crit Care 2009;15: 384-391.

3 Ronco C, Cicoira M, McCullough PA: Cardiorenal syndrome type 1: pathophysiological crosstalk leading to combined heart and kidney dysfunction in the setting of acutely decompensated heart failure. J Am Coll Cardiol 2012;60:1031-1042.

4 Zhou Q, Zhao C, Xie D, Xu D, Bin J, Chen P, Liang M, Zhang X, Hou F: Acute and acuteon-chronic kidney injury of patients with decompensated heart failure: impact on outcomes. BMC Nephrol 2012;13:51.

5 Cheng H, Chen YP: Clinical prediction scores for type 1 cardiorenal syndrome derived and validated in Chinese cohorts. Cardiorenal Med 2015;5:12-19.

6 Braunwald E, Bonow RO: Braunwald's Heart Disease: A Textbook of Cardiovascular Medicine, ed 9. Philadelphia, Saunders, 2012.

7 Bock JS, Gottlieb SS: Cardiorenal syndrome: new perspectives. Circulation 2010;121: 2592-2600.

8 Testani JM, Coca SG, Shannon RP, Kimmel SE, Cappola TP: Influence of renal dysfunction phenotype on mortality in the setting of cardiac dysfunction: analysis of three randomized controlled trials. Eur J Heart Fail 2011;13:1224-1230.

9 Smith GL, Lichtman JH, Bracken MB, Shlipak MG, Phillips CO, DiCapua P, Krumholz HM: Renal impairment and outcomes in heart failure: systematic review and meta-analysis. J Am Coll Cardiol 2006;47:1987-1996.

10 Bouquegneau A, Krzesinski JM, Delanaye P, Cavalier E: Biomarkers and physiopathology in the cardiorenal syndrome. Clin Chim Acta 2015;443:100-107.

11 Damman K, Van Veldhuisen DJ, Navis G, Vaidya VS, Smilde TD, Westenbrink BD, Bonventre JV, Voors AA, Hillege HL: Tubular damage in chronic systolic heart failure is associated with reduced survival independent of glomerular filtration rate. Heart 2010;96: 1297-1302.
12 Chen $\mathrm{HH}$, Anstrom KJ, Givertz MM, Stevenson LW, Semigran MJ, Goldsmith SR, Bart BA, Bull DA, Stehlik J, LeWinter MM, Konstam MA, Huggins GS, Rouleau JL, O’Meara E, Tang WH, Starling RC, Butler J, Deswal A, Felker GM, O'Connor CM, Bonita RE, Margulies KB, Cappola TP, Ofili EO, Mann DL, Davila-Roman VG, McNulty SE, Borlaug BA, Velazquez EJ, Lee KL, Shah MR, Hernandez AF, Braunwald E, Redfield MM: Low-dose dopamine or low-dose nesiritide in acute heart failure with renal dysfunction: the ROSE acute heart failure randomized trial. JAMA 2013;310:2533-2543.

13 Massie BM, O'Connor CM, Metra M, Ponikowski P, Teerlink JR, Cotter G, Weatherley BD, Cleland JG, Givertz MM, Voors A, DeLucca P, Mansoor GA, Salerno CM, Bloomfield DM, Dittrich HC: Rolofylline, an adenosine A1-receptor antagonist, in acute heart failure. N Engl J Med 2010;363:1419-1428.

14 O'Connor CM, Starling RC, Hernandez AF, Armstrong PW, Dickstein K, Hasselblad V, Heizer GM, Komajda M, Massie BM, McMurray JJ, Nieminen MS, Reist CJ, Rouleau JL, Swedberg K, Adams KJ, Anker SD, Atar D, Battler A, Botero R, Bohidar NR, Butler J, Clausell N, Corbalan R, Costanzo MR, Dahlstrom U, Deckelbaum LI, Diaz R, Dunlap ME, Ezekowitz JA, Feldman D, Felker GM, Fonarow GC, Gennevois D, Gottlieb SS, Hill JA, Hollander JE, Howlett JG, Hudson MP, Kociol RD, Krum H, Laucevicius A, Levy WC, Mendez GF, Metra M, Mittal S, Oh BH, Pereira NL, Ponikowski P, Tang WH, Tanomsup S, Teerlink JR, Triposkiadis F, Troughton RW, Voors AA, Whellan DJ, Zannad F, Califf RM: Effect of nesiritide in patients with acute decompensated heart failure. $\mathrm{N}$ Engl J Med 2011;365:32-43.

15 Bart BA, Goldsmith SR, Lee KL, Givertz MM, O'Connor CM, Bull DA, Redfield MM, Deswal A, Rouleau JL, LeWinter MM, Ofili EO, Stevenson LW, Semigran MJ, Felker GM, Chen HH, Hernandez AF, Anstrom KJ, McNulty SE, Velazquez EJ, Ibarra JC, Mascette $\mathrm{AM}$, Braunwald E: Ultrafiltration in decompensated heart failure with cardiorenal syndrome. N Engl J Med 2012;367:2296-2304.
16 Uttenthal O: NGAL: a marker molecule for the distressed kidney? Clin Lab Int 2005;29: 39-41.

17 Aghel A, Shrestha K, Mullens W, Borowski A, Tang WH: Serum neutrophil gelatinase-associated lipocalin (NGAL) in predicting worsening renal function in acute decompensated heart failure. J Card Fail 2010;16:49-54.

18 Alvelos M, Pimentel R, Pinho E, Gomes A Lourenco P, Teles MJ, Almeida P, Guimaraes JT, Bettencourt P: Neutrophil gelatinase-associated lipocalin in the diagnosis of type 1 cardio-renal syndrome in the general ward. Clin J Am Soc Nephrol 2011;6:476-481

19 Macdonald S, Arendts G, Nagree Y, Xu XF: Neutrophil gelatinase-associated lipocalin (NGAL) predicts renal injury in acute decompensated cardiac failure: a prospective observational study. BMC Cardiovasc Disord 2012; 12:8.

20 Yang X, Chen C, Tian J, Zha Y, Xiong Y, Sun Z, Chen P, Li J, Yang T, Ma C, Liu H, Wang $\mathrm{X}$, Hou FF: Urinary angiotensinogen level predicts $\mathrm{AKI}$ in acute decompensated heart failure: a prospective, two-stage study. J Am Soc Nephrol 2015;26:2032-2041.

21 Mortara A, Bonadies M, Mazzetti S, Fracchioni I, Delfino P, Chioffi M, Bersano C, Specchia G: Neutrophil gelatinase-associated lipocalin predicts worsening of renal function in acute heart failure: methodological and clinical issues. J Cardiovasc Med (Hagerstown) 2013;14:629-634.

22 Breidthardt T, Socrates T, Drexler B, Noveanu M, Heinisch C, Arenja N, Klima T, Zusli C, Reichlin T, Potocki M, Twerenbold R, Steiger J, Mueller C: Plasma neutrophil gelatinase-associated lipocalin for the prediction of acute kidney injury in acute heart failure. Crit Care 2012;16:R2.

23 Nymo SH, Ueland T, Askevold ET, Flo TH, Kjekshus J, Hulthe J, Wikstrand J, McMurray J, Van Veldhuisen DJ, Gullestad L, Aukrust P, Yndestad A: The association between neutrophil gelatinase-associated lipocalin and clinical outcome in chronic heart failure: results from CORONA. J Intern Med 2012;271:436443. 
24 Saeed M, Lim V, Tappia P, Cordova F, Malik A, Rigatto C, Shafer L, Sood M, Zieroth S: Urinary NGAL is not associated with renal function changes or hospitalization in ambulatory heart failure patients. Can J Cardiol 2012; 28:S280-S281.

25 Mcllroy DR, Wagener G, Lee HT: Neutrophil gelatinase-associated lipocalin and acute kidney injury after cardiac surgery: the effect of baseline renal function on diagnostic performance. Clin J Am Soc Nephrol 2010;5:211219.

26 Bolignano D, Donato V, Coppolino G, Campo S, Buemi A, Lacquaniti A, Buemi M: Neutrophil gelatinase-associated lipocalin (NGAL) as a marker of kidney damage. Am J Kidney Dis 2008;52:595-605.

27 Bolignano D, Coppolino G, Donato V, Lacquaniti A, Bono C, Buemi M: Neutrophil gelatinase-associated lipocalin (NGAL): a new piece of the anemia puzzle? Med Sci Monit 2010;16:A131-A135.

28 Velez JC: The importance of the intrarenal renin-angiotensin system. Nat Clin Pract Nephrol 2009;5:89-100.

29 Kobori H, Harrison-Bernard LM, Navar LG: Urinary excretion of angiotensinogen reflects intrarenal angiotensinogen production. Kidney Int 2002;61:579-585.

30 Liang KV, Williams AW, Greene EL, Redfield MM: Acute decompensated heart failure and the cardiorenal syndrome. Crit Care Med 2008;36:S75-S88.

31 Waring WS, Moonie A: Earlier recognition of nephrotoxicity using novel biomarkers of acute kidney injury. Clin Toxicol (Phila) 2011;49:720-728.

32 Damman K, Ng KCM, MacFadyen RJ, Lip GY, Gaze D, Collinson PO, Hillege HL, van Oeveren W, Voors AA, van Veldhuisen DJ: Volume status and diuretic therapy in systolic heart failure and the detection of early abnormalities in renal and tubular function. J Am Coll Cardiol 2011;57:2233-2241.

33 Damman K, Masson S, Hillege HL, Voors AA, van Veldhuisen DJ, Rossignol P, Proietti G, Barbuzzi S, Nicolosi GL, Tavazzi L, Maggioni AP, Latini R: Tubular damage and worsening renal function in chronic heart failure. JACC Heart Fail 2013;1:417-424.

34 Parikh CR, Mishra J, Thiessen-Philbrook H, Dursun B, Ma Q, Kelly C, Dent C, Devarajan P, Edelstein CL: Urinary IL-18 is an early predictive biomarker of acute kidney injury after cardiac surgery. Kidney Int 2006;70:199-203.

35 Verbrugge FH, Dupont M, Shao Z, Shrestha K, Singh D, Finucan M, Mullens W, Tang WH: Novel urinary biomarkers in detecting acute kidney injury, persistent renal impairment, and all-cause mortality following decongestive therapy in acute decompensated heart failure. J Card Fail 2013;19:621-628.

36 Jungbauer CG, Birner C, Jung B, Buchner S, Lubnow M, von Bary C, Endemann D, Banas B, Mack M, Boger CA, Riegger G, Luchner A: Kidney injury molecule- 1 and N-acetyl-beta-D-glucosaminidase in chronic heart failure: possible biomarkers of cardiorenal syndrome. Eur J Heart Fail 2011;13:1104-1110.
37 Hata N, Yokoyama S, Shinada T, Kobayashi N, Shirakabe A, Tomita K, Kitamura M, Kurihara $\mathrm{O}$, Takahashi $\mathrm{Y}$ : Acute kidney injury and outcomes in acute decompensated heart failure: evaluation of the RIFLE criteria in an acutely ill heart failure population. Eur J Heart Fail 2010;12:32-37.

38 Shirakabe A, Hata N, Kobayashi N, Shinada T, Tomita K, Tsurumi M, Matsushita M, Okazaki H, Yamamoto Y, Yokoyama S, Asai K, Mizuno K: Prognostic impact of acute kidney injury in patients with acute decompensated heart failure. Circ J 2013;77:687-696.

39 Roy AK, Mc GC, Treacy C, Kavanaugh E, Brennan A, Mahon NG, Murray PT: A comparison of traditional and novel definitions (RIFLE, AKIN, and KDIGO) of acute kidney injury for the prediction of outcomes in acute decompensated heart failure. Cardiorenal Med 2013;3:26-37.

40 Haase M, Muller C, Damman K, Murray PT, Kellum JA, Ronco C, McCullough PA: Pathogenesis of cardiorenal syndrome type 1 in acute decompensated heart failure: workgroup statements from the eleventh consensus conference of the Acute Dialysis Quality Initiative (ADQI). Contrib Nephrol 2013;182: 99-116.

41 Tang WH, Mullens W: Cardiorenal syndrome in decompensated heart failure. Heart 2010;96:255-260.

42 Koyner JL, Vaidya VS, Bennett MR, Ma Q, Worcester E, Akhter SA, Raman J, Jeevanandam V, O'Connor MF, Devarajan P, Bonventre JV, Murray PT: Urinary biomarkers in the clinical prognosis and early detection of acute kidney injury. Clin J Am Soc Nephrol 2010;5:2154-2165.

43 Steiner RW: Interpreting the fractional excretion of sodium. Am J Med 1984;77:699-702.

44 Hilberman M, Myers BD, Carrie BJ, Derby G, Jamison RL, Stinson EB: Acute renal failure following cardiac surgery. J Thorac Cardiovasc Surg 1979;77:880-888.

45 Yavuz I, Asgun FH, Bolcal C, Bingol H, Yokusoglu M, Baysan O, Ozgurtas T, Demirkilic U, Tatar H: Importance of urinary measurement of glutathione S-transferase in renal dysfunction patients after on- and off-pump coronary artery bypass surgery. Thorac Cardiovasc Surg 2009;57:125-129.

46 Pepin MN, Bouchard J, Legault L, Ethier J: Diagnostic performance of fractional excretion of urea and fractional excretion of sodium in the evaluations of patients with acute kidney injury with or without diuretic treatment. Am J Kidney Dis 2007;50:566-573.

47 Koyner JL, Garg AX, Coca SG, Sint K, Thiessen-Philbrook H, Patel UD, Shlipak MG, Parikh CR: Biomarkers predict progression of acute kidney injury after cardiac surgery. J Am Soc Nephrol 2012;23:905-914.

48 Arthur JM, Hill EG, Alge JL, Lewis EC, Neely BA, Janech MG, Tumlin JA, Chawla LS, Shaw AD: Evaluation of 32 urine biomarkers to predict the progression of acute kidney injury after cardiac surgery. Kidney Int 2014;85:431438.
49 Alge JL, Karakala N, Neely BA, Janech MG, Tumlin JA, Chawla LS, Shaw AD, Arthur JM: Urinary angiotensinogen and risk of severe AKI. Clin J Am Soc Nephrol 2013;8:184-193.

50 Hall IE, Stern EP, Cantley LG, Elias JA, Parikh CR: Urine YKL-40 is associated with progressive acute kidney injury or death in hospitalized patients. BMC Nephrol 2014;15:133.

51 Hall IE, Yarlagadda SG, Coca SG, Wang Z, Doshi M, Devarajan P, Han WK, Marcus RJ, Parikh CR: IL-18 and urinary NGAL predict dialysis and graft recovery after kidney transplantation. J Am Soc Nephrol 2010;21:189197.

52 Belcher JM, Garcia-Tsao G, Sanyal AJ, Thiessen-Philbrook H, Peixoto AJ, Perazella MA, Ansari N, Lim J, Coca SG, Parikh CR: Urinary biomarkers and progression of AKI in patients with cirrhosis. Clin J Am Soc Nephrol 2014;9:1857-1867.

53 Alge JL, Karakala N, Neely BA, Janech MG, Velez JC, Arthur JM: Urinary angiotensinogen predicts adverse outcomes among acute kidney injury patients in the intensive care unit. Crit Care 2013;17:R69.

54 Chen C, Yang X, Lei Y, Zha Y, Liu H, Ma C, Tian J, Chen P, Yang T, Hou F: Urinary biomarkers at the time of AKI diagnosis as predictors of progression of AKI among patients with acute cardiorenal syndrome. Clin J Am Soc Nephrol 2016, DOI: 10.2215/CJN. 00910116.

55 Ishani A, Xue JL, Himmelfarb J, Eggers PW, Kimmel PL, Molitoris BA, Collins AJ: Acute kidney injury increases risk of ESRD among elderly. J Am Soc Nephrol 2009;20:223-228.

56 Venkatachalam MA, Griffin KA, Lan R, Geng H, Saikumar P, Bidani AK: Acute kidney injury: a springboard for progression in chronic kidney disease. Am J Physiol Renal Physiol 2010;298:F1078-F1094.

57 Maisel AS, Mueller C, Fitzgerald R, Brikhan $\mathrm{R}$, Hiestand BC, Iqbal N, Clopton P, van Veldhuisen DJ: Prognostic utility of plasma neutrophil gelatinase-associated lipocalin in patients with acute heart failure: the NGAL EvaLuation Along with B-type NaTriuretic Peptide in acutely decompensated heart failure (GALLANT) trial. Eur J Heart Fail 2011; 13:846-851.

58 Palazzuoli A, Ruocco G, Pellegrini M, De Gori C, Del CG, Franci B, Nuti R, Ronco C: Comparison of neutrophil gelatinase-associated lipocalin versus B-type natriuretic peptide and cystatin C to predict early acute kidney injury and outcome in patients with acute heart failure. Am J Cardiol 2015;116:104-111.

59 Grodin JL, Perez AL, Wu Y, Hernandez AF, Butler J, Metra M, Felker GM, Voors AA, McMurray JJ, Armstrong PW, Califf RM, Starling RC, O'Connor CM, Tang WH: Circulating kidney injury molecule-1 levels in acute heart failure: insights from the ASCEND-HF trial (Acute Study of Clinical Effectiveness of Nesiritide in Decompensated Heart Failure). JACC Heart Fail 2015;3:777-785.

60 Taub PR, Gabbai-Saldate P, Maisel A: Biomarkers of heart failure. Congest Heart Fail 2010;16(suppl 1):S19-S24. 